\title{
CONCEPÇÕES DE HISTÓRIA LITERÁRIA NAS POLÊMICAS ENTRE ANTONIO CANDIDO E HAROLDO DE CAMPOS
}

\author{
CONCEPTS OF LITERARY HISTORY IN BETWEEN POLEMICS ANTONIO \\ CANDIDO AND HAROLD DE CAMPOS
}

Marcelo Fernando de Lima ${ }^{1}$

\begin{abstract}
Resumo
Na segunda metade do século XX, a crítica literária brasileira foi dominada por duas formas de compreender a história literária. Uma delas, ligada ao crítico Antonio Candido, concebia a história literária como uma sucessão de obras ao longo do tempo, imbuída por um forte senso de construção de identidade nacional, centrada na produção; a outra tendência, elaborada pelo poeta e crítico Haroldo de Campos, entendia a história literária a partir da sua atualização feita na recepção. O objetivo desse artigo é descrever essas duas tendências e mostrar sua permanência no atual discurso crítico brasileiro.
\end{abstract}

Palavras-chave: Literatura brasileira. Crítica. História literária. Cânone.

\begin{abstract}
In the second half of the $20^{\text {th }}$ century, Brazilian literary criticism was dominated by two ways of understanding literary history. One of them, linked to Antonio Candido, took history as a succession of literary works throughout the time, imbued with a strong sense of national identity construction, focusing on production; the other trend, established by the poet and critic Haroldo de Campos, understood the literary history as a product of reading response. The aim of this paper is to describe these two trends and to show their permanence in Brazilian criticism.
\end{abstract}

Keywords: Brazilian Literature. Criticism. Literary History. Canon.

\section{Introdução}

Ao longo da segunda metade do século XX, duas formas de classificar a história literária foram dominantes no Brasil, manifestando-se tanto no meio acadêmico, quanto em instâncias de consagração menos especializadas, como o jornalismo cultural. Antagônicas, elas repercutem nos discursos críticos até hoje e ainda influenciam, inclusive, a visão de determinados agentes sobre a tradição literária brasileira. A primeira delas, influenciada pela Sociologia e pela História, busca entender a literatura como um sistema integrado, evolutivo e diacrônico; tem na construção da nacionalidade

\footnotetext{
${ }^{1}$ Graduação em Comunicação Social - Jornalismo (1992, PUC-PR), Mestrado (1998) e Doutorado (2010) em Letras (UFPR). Professor adjunto da UTFPR-Curitiba. E-mail: marcelofernandodelima@yahoo.com.br
} 
e na autonomia do discurso literário a sua maior referência. A segunda forma, desenvolvida a partir de critérios estéticos e parciais, vê a história da literatura de maneira sincrônica, a partir de recortes seletivos, levando em conta a recepção das obras por determinados grupos de leitores.

O primeiro modo foi defendido, durante várias décadas, nos trabalhos do crítico Antonio Candido, desde a Formação de Literatura Brasileira, título publicado originalmente em 1959. A segunda foi formulada pelo poeta e crítico Haroldo de Campos também a partir dos anos 1950. As discussões teóricas e ideias de Campos, lançadas em artigos de jornal e ensaios em diversos livros durante quatro décadas, confluem em O sequestro do Barroco na Formação de Literatura Brasileira (1989), obra em que ataca diretamente a concepção de Candido.

Esse embate de teorias - de um lado o viés sociológico e a necessidade de entender a literatura como tradição e sucessão de obras, bem como instrumento de valorização do nacional; de outro, a valorização do estético e de uma poética da invenção, desarticulada de qualquer intenção nacionalista - foi um dos mais importantes da crítica brasileira no século XX. A disputa entre essas duas tendências, tanto na universidade, como nas páginas dos suplementos, teve vários desdobramentos nas últimas décadas.

O objetivo deste artigo é expor as principais diferenças entre as duas formas de encarar a história literária no Brasil e procurar entender em que medida elas ainda influenciam a atual crítica brasileira.

\section{A história como sistema}

Os dois volumes da Formação da Literatura Brasileira compreendem um período curto: do Arcadismo ao Romantismo, envolvendo a firmação do sistema literário no Brasil, considerado do ponto de vista sociológico. Diferente de outros livros que discutiam a história literária até então, o trabalho de Antonio Candido deu grande ênfase às análises de obras. Esse método, embora não alterasse o cânone nacional, acrescentou elementos mais elaborados para a sua fixação.

Influenciada por uma perspectiva de história literária como elemento de autonomia e reflexo da vida política do país, a obra estabelece o cânone a partir da relação com a construção da nacionalidade e da independência quanto às matrizes europeias. A noção de dependência cultural está presente desde o início do texto; 
Candido assinala que a literatura brasileira foi, em seu período de formação, um "galho secundário” da literatura portuguesa, esta também secundária quanto às literaturas francesa e inglesa.

A crítica à dependência acompanhou diversos escritos de Candido e de seus epígonos. No ensaio "Literatura e subdesenvolvimento", que apareceu originalmente na revista Argumento, em 1973, o crítico destacava:

\begin{abstract}
As nossas literaturas latino-americanas, como também as da América do Norte, são basicamente galhos das metropolitanas. E se afastarmos os melindres do orgulho nacional, veremos que, apesar da autonomia que foram adquirindo em relação a estas, ainda são em parte reflexas. No caso de países de fala espanhola e portuguesa, o processo de autonomia constitui, numa boa parte, em transferir a dependência, de modo que outras literaturas europeias não-metropolitanas, sobretudo a francesa, foram se tornando modelo a partir do século XIX, o que aliás ocorreu também nas antigas metrópoles, intensamente afrancesadas (CANDIDO, 2000, p. 151).
\end{abstract}

Na Formação, Candido estuda a literatura brasileira pela óptica da dependência e da superação de suas fontes europeias. Ele entende, justamente por isso, que a história literária brasileira só teria começado efetivamente com o Arcadismo, período em que passaram a operar as condições essenciais para o funcionamento de um sistema literário, com a presença: 1) de polo produtor, 2) um conjunto de leitores e 3) um sistema simbólico compartilhado. Trata-se da relação de interdependência autorobra-público, na qual se pressupõe a ideia marxista segundo a qual as condições materiais de uma sociedade (infraestrutura) determinam a sua produção cultural (superestrutura). Assim, a literatura brasileira só passou a existir efetivamente depois de as condições materiais mínimas terem sido construídas. Além disso, a abordagem de Candido insiste na ideia de que a literatura brasileira está associada ao movimento de independência, influenciado pela Revolução Francesa, na segunda metade do século XVIII.

Autores que desenvolveram suas obras anteriormente ao Arcadismo não são contemplados pela Formação de Candido, que entende a inexistência de um sistema literário local antes desse período. A questão mais polêmica se deu em torno de Gregório de Matos, que tem obtido destaque na crítica brasileira desde a segunda metade do século XX. Candido entende que a obra de Matos não faz parte de um sistema literário nacional. O crítico afirma que, 
“[...] embora tenha permanecido na tradição local da Bahia, ele não existiu literariamente (em perspectiva histórica) até o Romantismo, quando foi redescoberto, sobretudo graças a Varnhagen; e só depois de 1882 e da edição de Vale Cabral pôde ser devidamente avaliado. Antes disso, não influiu, não contribuiu para formar o nosso sistema literário, e tão obscuro permaneceu sob os seus manuscritos, que Barbosa Machado, o minucioso erudito da Biblioteca Lusitana (1741-1758), ignorava-o completamente [...]" (CANDIDO, 1997, p. 24).

\section{Uma história sincrônica}

A ausência de Gregório de Matos na história literária de Candido foi o principal foco da crítica de Haroldo de Campos no ensaio O sequestro do Barroco na Formação da Literatura Brasileira, de 1989. Campos apresenta uma concepção de história literária sincrônica, que leva em consideração as várias leituras a que um determinado autor foi submetido, bem como sua influência na literatura nacional. Prezando a recepção, Campos aproxima-se da noção de história literária defendida pelo crítico Hans Robert Jauss, um dos fundadores da Estética da Recepção.

Para o teórico alemão, a história literária tradicional, influenciada pelo Positivismo, representa apenas uma idealização da literatura em determinado período. Assim como a história tradicional na modernidade tem como propósito a formação da identidade nacional, a história literária torna o cânone submisso a critérios de nacionalidade e a esquemas evolutivos. A proposta de Jauss é pensar uma nova história literária, levando em consideração o polo da leitura, e não apenas o autor ou a obra. Para ele, a literatura não pode ser percebida apenas do ponto de vista diacrônico, cronológico, fixada no passado, mas em movimento, pois a recepção é uma forma de reabilitar autores e atualizar suas obras (JAUSS, 1994).

Haroldo de Campos trilha um caminho semelhante, ao sugerir a criação de uma história literária não-linear, que leva em conta a recepção das obras em determinada época. No lugar de um critério que idealiza a “totalidade histórica”, admite a possibilidade de ela ser abordada de forma seletiva e plural. Fazendo uma crítica à abordagem de Candido, Haroldo de Campos afirma que, apesar de não ter “existido” em sua época, Gregório de Matos é fundamental para a formação da literatura brasileira de linhagem satírica e inventiva:

Estamos, pois, diante de um verdadeiro paradoxo borgiano, já que à “questão da origem" se soma a da identidade ou pseudoidentidade de um autor “patronímico". Um dos maiores poetas brasileiros anteriores à Modernidade, aquele cuja existência é justamente mais fundamental para que possamos 
coexistir com ela e nos sentirmos legatários de uma tradição viva, parece não ter existido literariamente "em perspectiva histórica". (CAMPOS, 1989, p. $10)$.

Campos critica a Formação por considerar que o estudo de Candido entende a história literária pelo viés evolutivo-teleológico:

[...] seja pela "ideia condutora" de "individualidade” ou "espírito nacional”, a operar, sempre com dinamismo teleológico, num encadeamento de uma sequência acabada de eventos (e a culmina necessariamente num "classicismo nacional"), correspondente, no plano político, a "outro instante de plenitude”, a conquista da “unidade da nação”. (CAMPOS, 1989, p. 13).

É preciso, no entanto, entender o lugar de onde Haroldo de Campos profere seu discurso em defesa do Barroco. Mais do que um teórico da literatura, ele foi um poeta que tentou criar sua própria linhagem literária, ao "inventar" seus precursores e fazer uma “cruzada” em nome da inclusão de determinados autores e poéticas ao cânone nacional. Numa poética que, em suas próprias palavras, dá grande ênfase à materialidade do signo linguístico, mais ao significante do que ao significado, Haroldo de Campos e os intelectuais ligados à Poesia Concreta fizeram uma seleção da poesia brasileira e mundial, tentando encontrar precursores. Trata-se de um tipo de crítica que evidencia o clima de liberdade interpretativa que se instaurou ao longo do século XX, com a defesa dos objetos artísticos como sendo obras abertas (ECO, 2001).

A maneira de operar de Campos encontra paralelo na obra crítica de Ezra Pound, que privilegiou a formação de uma história da poesia a partir da leitura sincrônica, como pode ser visto no seu $A B C$ da Literatura. Valores como "novidade” e “radicalidade” são frequentes nos escritos desses dois autores, cuja defesa, não raro, assume "tom de manifesto e de polêmica” (PERRONE-MOISÉS, 1998, p. 153). Pound foi um dos precursores de um tipo de história literária que pressupõe a elaboração de um “paideuma” - conjunto de obras que se tem como referência e que tem valor de cânone - para uso particular ou geral. No livro ABC da Literatura (POUND, 2006), o poeta norte-americano adota critérios seletivos e particulares para a leitura da tradição literária, buscando superar categorias tradicionais, como as determinações temporais ou geográficas.

No embate entre Haroldo de Campos e Antonio Candido, os lugares de fala são determinantes. O Movimento da Poesia Concreta, de que Haroldo de Campos foi um dos ideólogos, representou a busca de um ideal artístico distante das preocupações 
teóricas de Candido, voltado para uma teoria que apontasse a superação da dependência e da literatura como discurso empenhado do ponto de vista político. Uma das características da Poesia Concreta foi a afirmação de uma tradição de autores que valorizasse a materialidade da palavra poética. Entende-se por tradição não apenas o universo textual da literatura brasileira, mas a produção em diversos idiomas. O movimento evidenciou o diálogo com outras tradições culturais, de maneira bastante livre, fazendo da tradução - ou "transcriação", conforme defende Haroldo de Campos um dos seus instrumentos mais importantes. A tradução é entendida como uma forma de leitura, crítica e atualização.

A Poesia Concreta buscou a ampliação do conceito de literatura, abrindo-se para as tecnologias da sociedade industrial, a oralidade e as artes visuais. Em alguns momentos, esteve na linha de frente da produção cultural e teórica, como ocorreu, no final dos anos 1960, com sua influência sobre o movimento Tropicalista. O diálogo com a música, as artes plásticas, a publicidade e os produtos de uma sociedade povoada pelos novos "meios de reprodutibilidade técnica” ajudou a caracterizar a Poesia Concreta como uma prática artística e teórica experimental e inovadora (AGUILAR, 2005).

Na definição de Décio Pignatari, um dos integrantes do grupo, o poeta é um “designer da linguagem”, ou seja, um artista capaz de articular, no discurso poético, várias linguagens. Assim, os poetas concretos compuseram diversas antologias e revisões das tradições poéticas, tentando tirar do purgatório crítico aqueles autores e textos pouco valorizados pelo cânone nacional. Os textos "resgatados” ajudariam a iluminar a própria produção do movimento e inseri-la em uma nova história literária. Uma das estratégias foi a realização de revisões de autores pouco valorizados nas histórias literárias - seja por meio de ensaios isolados, seja por trabalhos monográficos. Outra ação foi utilizar a "transcriação” de poemas a partir de diversos idiomas, procurando “preservar” sua inventividade formal nas versões para o português.

Ainda no final da década de 1960, Haroldo de Campos passou a dialogar com as ideias de alguns teóricos e movimentos artísticos para a sua operação de revisão da história literária, entre eles Ezra Pound, Oswald de Andrade, Jacques Derrida e as propostas da Estética da Recepção. Publicado quase trinta anos depois, O sequestro do Barroco reúne todas essas ideias, formando uma noção de história literária baseada na seletividade e na superação dos modelos europeus a partir da antropofagia oswaldiana. Sob a influência de Pound, Haroldo de Campos entendeu a tradição pelo recorte da 
invenção; com a antropofagia de Oswald de Andrade, procurou superar a noção de dependência, presente na crítica da época.

Quanto ao trabalho de revisão e modificação do cânone nacional, a crítica de Haroldo de Campos teve o mérito de ter resgatado vários autores do limbo - a começar pelo enfant térrible do Modernismo, Oswald de Andrade, na década de 1960. Haroldo empreendeu diversos projetos com seu irmão, Augusto de Campos, entre os quais os estudos sobre as obras poéticas de Sousândrade e de Pedro Kilkerry, autores considerados até então secundários no cânone nacional. A revisão de Kilkerry é exemplar. $\mathrm{Na}$ sua crítica, o que interessou destacar foi a inventividade do poeta, inserindo-o na linhagem de outros poetas-inventores.

É interessante notar, nessa forma de leitura da história literária, o uso do expediente da colagem dadaísta. Em uma das montagens gráficas de seu $O$ Anticrítico (1986), Augusto de Campos põe, uma à frente da outra, as imagens de Ezra Pound (p. 174) e Gertrude Stein (p. 175), no ensaio “Gertrude é uma Gertrude”. As imagens mostram semelhanças entre os dois. No ensaio, Augusto faz um paralelo entre as duas poéticas. A mesma estratégia é usada na aproximação entre o poeta simbolista brasileiro Maranhão Sobrinho (1879-1915) e Stéphane Mallarmé (1842-1898). O título do ensaio é “Stefânio Maranhão Mallarmé Sobrinho”, fazendo a brincadeira com a colagem dos nomes, com a criação de um suposto parentesco entre os dois poetas e a mistura dos poemas desses autores. Assim, a leitura de Maranhão Sobrinho “ajuda” Augusto a traduzir para o português a poesia de Mallarmé; a recepção de Mallarmé ilumina a leitura dos poemas de Maranhão Sobrinho, que pertencem a uma linhagem inventiva da poesia, assim como "gregório, sousândrade, kilkerry/aos voos da blasfêmia esparsos no futuro/bright brazilians blasting at bastards” (CAMPOS, 1986, p. 154).

Outro ponto a se considerar é o trabalho de tradução do grupo, um dos mais importantes da literatura brasileira. Mais do que uma simples atividade intelectual, a tradução tem um sentido político. Ela serve para reafirmar as linhagens de poetas críticos esparsas em várias literaturas ocidentais e orientais. Assim, principalmente Haroldo e Augusto de Campos se dedicaram a traduzir trechos de obras em diversos idiomas, muitas delas notórias por sua dificuldade e por nunca terem sido vertidas para o português. Mais do que enciclopédico, o trabalho tradutório dos poetas concretos tem um sentido seletivo, como sua história literária, sua "biblioteca pessoal”.

Dessa forma, muitas das traduções são parciais, como é o caso de excertos de obras de James Joyce, Dante, Maiakovski, Rilke, Goethe, Homero, poemas bíblicos, 
provençais, poemas japoneses e chineses. De Joyce, os irmãos Campos traduziram apenas alguns trechos do "Finnegans Wake", compondo um "panorama” do escritor irlandês. Haroldo de Campos fez uma nova versão de "Eclesiastes", "Livro de Jó” e “Gênesis”. De Maiakovski, Haroldo e Augusto de Campos deram preferência aos poemas que destacaram a experiência formal.

\section{Literatura como missão}

A posição de Antonio Candido, que iniciou suas atividades como crítico literário nos anos 1940, é bastante diversa. De formação sociológica e pertencente a uma geração influenciada pelas mudanças políticas da década de 1930, em que o debate sobre a identidade nacional passou a ser chave para a cultura brasileira (MOTA, 1994), Candido entende a literatura brasileira do pondo de vista evolutivo e da formação da nacionalidade. Trata-se, no seu entendimento, de um sistema que se constrói em paralelo ao das literaturas europeias, que lhes serviram de modelo. A primeira questão a se notar é que Candido admite a existência de dependência de um sistema hegemônico representado pelo agente externo. A literatura brasileira, "galho secundário da portuguesa”, repleta de "gosto provinciano" e “falta do senso de proporções”, é vista deliberadamente como inferior: "Comparada às grandes, a nossa literatura é pobre e fraca. Mas é ela, e não outra, que nos exprime. Se não for amada, não revelará sua mensagem; e se não a amarmos, ninguém o fará por nós” (CANDIDO, 1997, p. 10). Sua proposta crítica é comprometida com a construção de uma literatura nacional de qualidade.

Essa postura é estratégica no pensamento de Candido e se desdobra em estudos realizados posteriormente à publicação da Formação. A missão do crítico é mostrar que a literatura brasileira, desde a sua formação como sistema, busca a independência em relação à matriz europeia. Essa independência, conforme sinaliza Candido, só foi conquistada no século XX, sob um projeto brasileiro de modernidade mais amplo, envolvendo vários setores da sociedade. O grande passo para a conquista da autonomia artística nacional, conforme o projeto de Candido, teria sido o Modernismo, responsável pela criação de uma linguagem literária brasileira. Cabe destacar que boa parte da trajetória de Candido e de seu trabalho como orientador, pela Universidade de São Paulo, de muitos pesquisadores da literatura, foi construir um discurso crítico reforçando o papel do Modernismo na formação da nacionalidade. 
A noção de superação da dependência está presente de forma destacada no ensaio "Literatura e subdesenvolvimento", em que Candido localiza a autonomia do discurso literário latino-americano a partir da segunda metade do século XX, com a formação de uma consciência aguda em relação ao subdesenvolvimento. É nesse período que alguns países da América Latina produziram obras de importância no cenário local e tiveram visibilidade internacional, superando a noção de cópia das matrizes culturais europeias.

Outro ponto importante - e que é decisivo para a escolha dos autores e do cânone literário - é o caráter empenhado da literatura brasileira conforme a postulação de Candido. Para o crítico, o desenvolvimento da literatura como sistema diz respeito às questões políticas de afirmação da identidade nacional. Trata-se de uma questão de conteúdo referencial e não necessariamente de procedimento estético. Segundo Candido, os produtores da literatura brasileira na fase da sua formação tinham "[...] a consciência, ou a intenção, de estar fazendo um pouco da nação ao fazer literatura” (CANDIDO, 1997, p. 18).

Esse fato - continua Candido - resultou numa característica geral bastante marcante dessa literatura, que é a constatação de que seus textos são fáceis, objetivando a comunicação imediata com o leitor. Feita em seus primórdios mais para ser ouvida do que lida, a literatura brasileira não tem em suas origens, na opinião do crítico, autores que utilizem a linguagem de maneira engenhosa e difícil. Dessa forma, privilegia o conteúdo referencial, em detrimento da experimentação da linguagem.

Outro ponto a ser destacado é a “certidão de nascimento" da literatura brasileira. Para Candido, nos séculos XVI e XVII as manifestações literárias que ocorreram no país não chegaram a compor um sistema articulado. Ela só foi se tornar um sistema literário, defende Candido, no final do século XVIII, em virtude do surgimento do engajamento literário dos poetas ligados ao Arcadismo. A emergência do sistema literário brasileiro coincide, diz Candido, com o movimento de luta pela independência. O crítico defende que a literatura produzida nessa época tinha objetivo duplo: promover a conscientização política e criar uma linguagem brasileira, que se diferenciasse da produção da metrópole:

A literatura do Brasil, como a dos outros países latino-americanos, é marcada por esse compromisso com a vida nacional no seu conjunto, circunstância que inexiste nas literaturas dos países da velha cultura. Neles, os vínculos neste sentido são os que prendem necessariamente as produções do espírito ao conjunto das produções culturais; mas não a consciência, ou a intenção, de 
estar fazendo um pouco da nação ao fazer literatura. (CANDIDO, 1997, p. 18).

Com esse fato, Candido justifica a exclusão de Gregório de Matos da Formação da Literatura Brasileira, fato entendido por Haroldo de Campos não como questão de método, mas como uma plataforma política e, de certa forma, incoerente com a própria obra de Candido. O argumento de Campos é que Candido "sequestrou” o Barroco de sua história literária por privilegiar uma tradição literária que tinha por meta a comunicação fácil, sem oferecer obstáculos ao leitor.

Segundo Campos (1989), o autor da Formação teria secundado a importância das funções da linguagem mais ligadas à invenção literária, como a função poética e metalinguística, destacando, em vez disso, a literatura empenhada do Arcadismo e do Romantismo. Campos aponta ainda contradições no ensaio "Dialética da Malandragem”, estudo de Candido sobre Memórias de um sargento de milícias, de Manuel Antonio de Almeida. Para Campos, existe uma relação visceral entre a literatura de Almeida e a de Gregório de Matos, que não é apontada no texto de Candido:

\footnotetext{
Nesse novo desenho, não constelar, mosaical, o antes inexistente "Boca do Inferno" passa a ter voz e vez. É ele agora um dos precursores da comicidade “malandra” em nossa literatura, valorizado, nessa óptica renovada, não pelo seu veio sério-estético da poesia lírica, amorosa, religiosa, mas pela sátira desabusada. (CAMPOS, 1989, p. 72).
}

\section{Considerações finais}

É difícil comparar as concepções de história literária apresentadas acima, já que evidenciam pontos muito diversos: Antonio Candido, influenciado pelo discurso sociológico e pela ideia de totalidade histórica, classifica as obras literárias a partir de sua representatividade do social; Haroldo de Campos, assumindo uma posição deliberadamente fragmentada, destaca o recorte da "invenção" e da "radicalidade” da linguagem.

Apesar disso, é possível afirmar que a noção de história literária “total”, como a defendida por Candido, entrou em crise nas últimas décadas. Em seu lugar, na esteira das teorias pós-modernas e do culturalismo, a tendência atual vislumbra uma história literária cada vez mais fragmentada, como a defendida por Haroldo de Campos. Assim, a história literária deixa de ser pensada de forma fechada, em torno de conceitos totalizantes, para constantes revisões e definições do cânone. 
Hoje, a história literária, influenciada pela história das mentalidades, não se resume apenas à literatura erudita, mas apresenta um diálogo constante com a história cultural e acompanha o movimento dos estudos literários em questionar as intenções políticas na firmação dos cânones. Assim, trata-se da coexistência de histórias literárias, que buscam entender as manifestações literárias no plural.

\section{Referências}

AGUILAR, Gonzalo. Poesia concreta brasileira: as vanguardas na encruzilhada modernista. São Paulo: Edusp, 2005.

CAMPOS, Augusto de. O anticrítico. São Paulo: Companhia das Letras, 1986.

CAMPOS, Haroldo de. O sequestro do Barroco na Formação da Literatura Brasileira. Salvador: Fundação Casa de Jorge Amado, 1989.

CANDIDO, Antonio. Formação da Literatura Brasileira: momentos decisivos. 2 volumes. Belo Horizonte: Itatiaia, 1997.

CANDIDO, Antonio. Literatura e subdesenvolvimento. In: Educação pela noite e outros ensaios. Rio de Janeiro: Ática, 2000.

ECO, Umberto. Obra aberta. São Paulo: Perspectiva, 2001.

JAUSS, Hans Robert Jauss. A história da literatura como provocação à história literária. São Paulo: Ática, 1994.

MOTA, Carlos Guilherme. Ideologia da cultura brasileira (1933-1974). São Paulo: Ática, 1994.

PERRONE-MOISÉS, Leyla. Altas literaturas: escolha e valor na obra crítica de escritores modernos. São Paulo: Companhia das Letras, 1998.

WAIZBORT, Leopoldo. Esquema (parcial) de Antonio Candido. Novos Estudos Cebrap, n. 64. nov. 2002, p. 177-188. 